\title{
A Detailed Study on Earthquake Resistant Buildings on Ground Surface by Using E-Tabs
}

\author{
K. Hemanth ${ }^{1}$, Shamshad Begum ${ }^{2}$ \\ ${ }^{*}$ M.Tech Scholar, Intell Engineering College, Anantapur, Andhra Pradesh, India \\ ${ }^{2}$ Assistant Professor, Intell Engineering College, Anantapur, Andhra Pradesh, India
}

\begin{abstract}
Article Info

Volume 8, Issue 4

Page Number : 619-625

Publication Issue

July-August-2021

\section{Article History}

Accepted : 12 Aug 2021

Published : 22 Aug 2021

In the present investigation to discover the impact of level and slanting ground on structure execution ground inclines of 00 and 100 are considered in displaying of structures of tallness G+15 RCC structures having material properties M40 grade for cement and Fe500 for fortifying steel and structures measurements are length $=6 \times 10=60 \mathrm{~m}$, width $=6 \times 5=30 \mathrm{~m}$ and statures of G+15 is $48 \mathrm{~m}$ from the plinth level, the help conditions are picked to be fixed base and establishment profundity is considered as $2 \mathrm{~m}$ beneath the ground level structures are demonstrated utilizing ETABS in seismic zones II, III, IV, V according to IS 1893-2002 strategies utilized for seismic burden age are Linear static examination, Response range examination and Time history examination. The outcomes are appeared as far as charts and tables.

Keywords : Earthquake Resistant Structures, Tallness, Compaction, Deterioration, Durability
\end{abstract}

\section{INTRODUCTION}

By and large the structures are built on level ground. In certain regions the ground itself is a slant. In that condition it is hard to uncovering, levelling and it is pricey .Due to the shortage of level ground architects began development on messy ground itself. A portion of the uneven territories are increasingly inclined to the tremor. Around there for the most part development works completed by locally accessible materials, for example, bamboo, timber, block, RCC and furthermore they gave increasingly imperative to the light weight materials for the development of houses. As the populace thickness increments at bumpy district necessity of structure likewise increments. The prominence and request of multistory structure on bumpy slant is likewise increments.

The unsymmetrical structures require incredible consideration in the investigation and plan under the activity of seismic excitation. Past seismic tremors in which, structures situated close to the edge of a stretch of slopes or on slanting ground endured genuine harms. The shorter segment draws in more powers and experiences harm, when exposed to tremors. Different issues related with slope structures are, extra horizontal earth weight at different levels, 
incline insecurity, distinctive soil profile yielding inconsistent settlement of establishment.
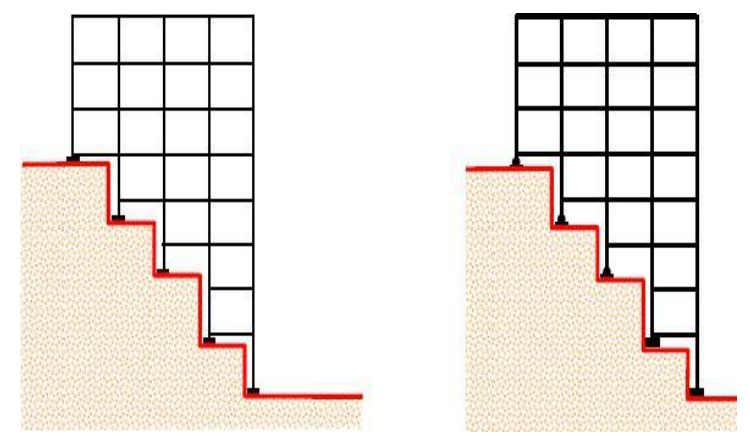

Fig: 1.1 : Building on sloping grounds

Origin of earthquake: Sudden movement on faults is responsible for earthquakes. An earthquake is simply the vibrations caused by the blocks of rock on either side of a fault rubbing against each other as they move in opposite directions. Bigger the movement of faults bigger the earthquake.

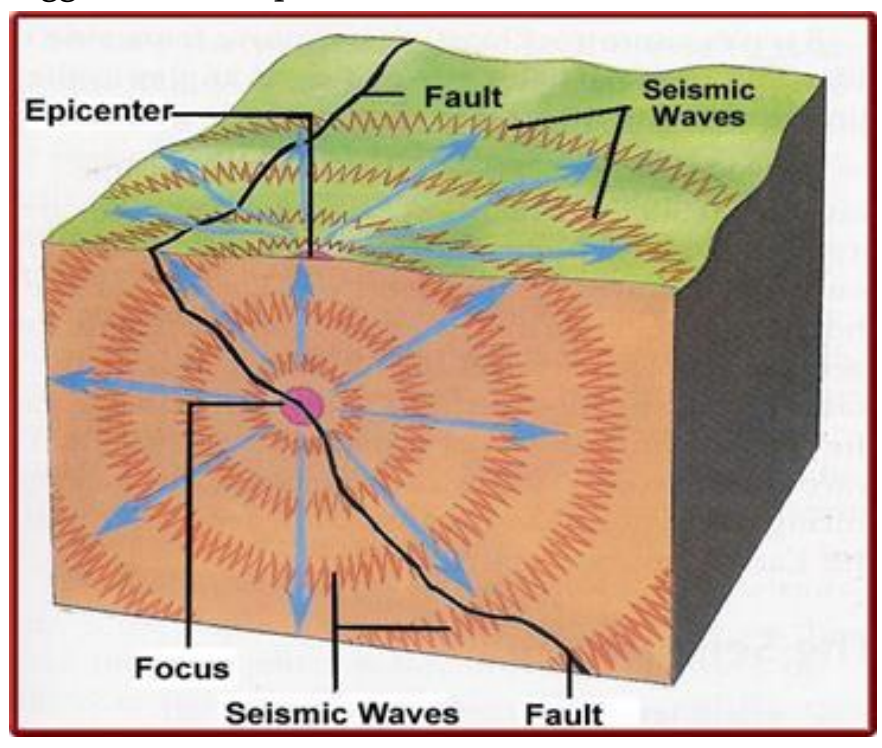

Fig: 1.2: Origin of earthquake from Earth

\section{Seismic zones India:}

Based on magnitude of the earthquake India is classified into four zones (II, III, IV, and V) where zone $\mathrm{V}$ is high severity zone
Table 1 : Zone Factor, Z

\begin{tabular}{ccccc}
\hline $\begin{array}{c}\text { Seismic } \\
\text { Zone }\end{array}$ & II & III & IV & V \\
$\begin{array}{c}\text { Seismic } \\
\text { Intensity }\end{array}$ & Low & Moderate & Severe & $\begin{array}{c}\text { Very } \\
\text { Severe } \\
Z\end{array}$ \\
\hline
\end{tabular}

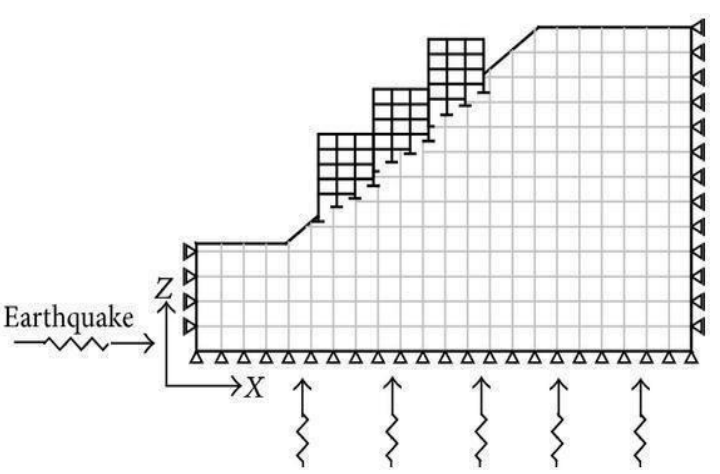

Fig 1.3: effect of seismic waves on structures

Disadvantages on structures built on sloping hill surfaces

1. Shorter sections are exposed to higher seismic powers

2. Lateral Soil weight ought to be considered in structures

3. Excavation of ground is troublesome and exorbitant

4. Lateral supporting frameworks like sheet heaps ought to be received in removal

5. Laying of roadways to slope stop is exorbitant

6. Accessibility of structures is troublesome

7. Costly waste frameworks ought to be

8. received

9. More inclined to catastrophic events like avalanches and so forth

10. Subjected to high wind speeds

11. Dynamic investigation ought to be done

12. utilizing soil structure association 


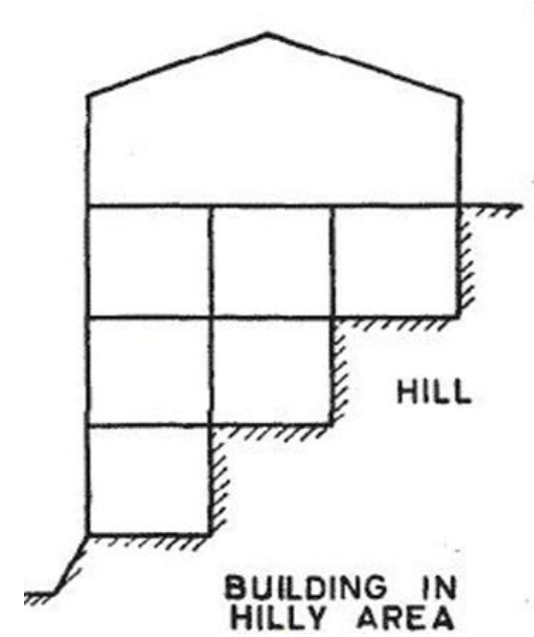

Fig 1.4: Buildings constructed on hilly slopes as per IS : 1893-1984

\section{LINEAR STATIC ANALYSIS}

Relocations, strains, stresses, and response powers under the impact of connected burdens are determined. A progression of suppositions are made as for a direct static examination:

Little Deflections Determine whether the avoidances acquired or anticipated are little in respect to the size of the structure. Little Rotations 2In straight codes all revolutions are thought to be little. Any edge estimated in radians ought to be little enough that the digression is around equivalent to the point.

Material Properties Linear solvers expect that all material carries on in a direct flexible way. A few materials have a non-straight versatile conduct, and in spite of the fact that they don't really yield.

\section{Time history technique:}

The utilization of this strategy will be on a proper ground movement and will be performed utilizing acknowledged standards of elements. In this technique, the scientific model of the structure is exposed to increasing velocities from seismic tremor records that speak to the normal quake at the base of the structure.

\section{Response range strategy:}

The word range in designing passes on the possibility that the reaction of structures having an expansive scope of periods is condensed in a solitary chart. This strategy will be performed utilizing the plan range determined in code or by a site-explicit structure range for a structure arranged at a task site. The benefits of damping for structure might be taken as 2 and 5 percent of the basic, for the motivations behind powerful investigation of steel and fortify solid structures, individually.

\section{Response Spectrum Analysis according to May be: 1893-2002}

This strategy is otherwise called modular technique or mode superposition strategy. It depends on the possibility that the reaction of a structure is the superposition of the reactions of individual methods of vibration, every mode reacting with its own specific distorted shape, its own recurrence, and with its own modular damping.

As indicated by IS 1893(Part-1):2002, skyscraper and sporadic structures must be broke down by reaction range strategy utilizing plan spectra Sufficient modes to catch with the end goal that at any rate $90 \%$ of the taking an interest mass of the structure (in every one of two symmetrical guideline level bearings) must be considered for the investigation. Be that as it may, in this strategy, the plan base shear (VB) will be contrasted and a base shear $(\mathrm{Vb})$ determined utilizing a basic period $\mathrm{T}$. On the off chance that VB is not exactly $\mathrm{Vb}$, all reaction amounts are (for instance part powers, removals, story powers, story shears and base responses) duplicated by $\mathrm{VB} / \mathrm{Vb}$.

\section{Modal mix according to Seems to be: $1893-2002$}

Modular Response amounts for every method of reaction might be consolidated by the total quadratic $\operatorname{mix}(\mathrm{CQC})$ procedure or by taking the square base of 
the total of the squares (SRSS) of every method of the modular qualities or total whole (ABS) technique.

(I) CQC technique: The pinnacle reaction amounts will be consolidated according to the total quadratic $\operatorname{mix}(\mathrm{CQC})$ strategy.

$$
\begin{aligned}
\lambda & =\sqrt{\sum_{i=1}^{r} \sum_{j=1}^{r} \lambda_{\mathrm{i}} \rho_{\mathrm{ij}} \lambda_{\mathrm{j}}} \\
\text { where } & \\
r= & \text { Number of modes being considered, } \\
\rho_{\mathrm{ij}}= & \text { Cross-modal coefficient, } \\
\lambda_{\mathrm{i}}= & \begin{array}{l}
\text { Response quantity in mode } i \text { ( including } \\
\text { sign ), }
\end{array} \\
\lambda_{\mathrm{j}}= & \begin{array}{l}
\text { Response quantity in mode } j \text { ( including } \\
\text { sign ), }
\end{array}
\end{aligned}
$$

(ii) SRSS method: If the building does not have closely spaced modes, then the peak response quantity due to all modes considered shall be obtained as

$$
\lambda=\sqrt{\sum_{k=1}^{r}\left(\lambda_{k}\right)^{2}} \begin{aligned}
\text { where } & \\
\lambda_{k} & =\text { Absolute value of quantity in mode } k, \text { and } \\
r & =\text { Number of modes being considered. }
\end{aligned}
$$

(iii) ABS method: If the building has a few closely spaced modes, then the peak response quantity due to all modes considered shall be obtained as

$$
\lambda^{*}=\sum_{c}^{r} \lambda_{\mathrm{c}^{\prime}}
$$

Where, the summation is for the closely-spaced modes only. This peak response quantity due to the closely spaced modes $\left(\lambda^{*}\right)$ is then combined with those of the remaining well-separated modes by the method described above.

\section{El Centro earthquake for time history analysis}

The 1940 El Centro tremor happened at 21:35 Pacific Standard Time on May 18 (05:35 UTC on May 19) in the Imperial Valley in southeastern Southern California close to the worldwide outskirt of the United States and Mexico. It had a minute extent of
6.9 and a greatest saw power of X (Extreme) on the Mercalli force scale. The seismic tremor was the aftereffect of a break along the Imperial Fault, with its focal point 5 miles $(8.0 \mathrm{~km})$ north of Calexico, California, The occasion caused noteworthy harm in the towns of Brawley, Imperial, El Centro, Calexico and Mexicali and was in charge of the passings of nine individuals

\section{Mass hotspot for the count of seismic loads:}

1. $100 \%$ of Dead loads from auxiliary individuals and block work are considered

2. $50 \%$ of live loads/forced burdens are considered

\section{About ETABS}

The displaying and the investigation of the structure edges were done utilizing business programming ETABS. The significant highlights of this product are as per the following:

- ETABSis broadly utilized programming bundle from Computers and Structures, Inc for structure structures.

- $\quad$ ETABShas completely graphical UI. It is utilized to create the model, which would then be able to be dissected.

The ETABS motor: It is a universally useful computation motor for auxiliary investigation and coordinated steel, solid, timber and aluminum.

\section{LITERATURE SURVEY}

B.G. Birajdar1, S.S. Nalawade2. Made an examination on seismic investigation of structures laying on slopingground by considering $24 \mathrm{RC}$ structures with three differentconfigurations like, Step back structure, Step back Set back structure and Set back structure arepresented. $3-\mathrm{D}$ examination including torsional impact has been done by utilizing responsespectrum 
technique. The dynamic reaction properties for example central timeframe, top storeydisplacement and, the base shear activity prompted in segments have been examined with referenceto the reasonableness of a structure arrangement on slanting ground. In the present investigation, three gatherings of structure ( for example arrangements) are considered, out of which twoare laying on slanting ground and third one is on plain ground. The initial two are venture back buildingsand venture backmisfortune structures; and third is the hindered structure. The incline of ground is 27 degreewith level, which is neither excessively steep or nor excessively level. The tallness and length of structure in aparticular example are in various of squares ( in vertical and flat course), the size of square isbeing kept up at $7 \mathrm{~m} \times 5 \mathrm{~m} \times 3.5 \mathrm{~m}$. The profundity of balance subterranean level is taken as 1.75 mwhere, the hard stratum is accessible. The presentation of STEP back structure during seismic excitation could demonstrate morevulnerable than different arrangements of structures. Thus, Step back Set back structures are observed to be less vulnerable than Step back structure against seismic ground motion. In Step back structures and Step back-Set back structures, it is seen that extraordinary left column at ground level, which are short, are the most exceedingly awful influenced. Exceptional consideration ought to be given to these segments in structure and specifying.

Likhitharadhya Y R1, Praveen J V2, Sanjith J3, Ranjith A4 performed Seismic Analysis of MultiStory Building Resting On Flat Ground and Sloping Ground In this examination, G+ 10 stories RCC building and the ground slant differing from 100 to 300 have been considered for the investigation. The seismic examination was finished by the reaction range investigations have been done according to IS:1893(part 1): 2002. The outcomes were gotten as top story uprooting, Story Acceleration, Base shear and Mode period. It is seen that short section is influenced more during the quake. Base shear is most extreme at 200 incline contrasted with other models. Period additionally increases. From the examination, Story dislodging is decline with increment in slant angle. From the investigation, Story Acceleration is decline with increment in slant angle. Acceleration is greatest in story-11 when contrasted with story- 1 in every other model along $\mathrm{x}$ and $\mathrm{y}$-course.

Dr. R. B. Khadiranaikar1 and Arif Masali2 survey on Seismic execution of structures laying on inclining ground and the ends drawn are1. Venture back structures produce higher base shear, higher estimation of timespan, higher estimation of top story uprooting contrasted with venture back set back structure. During seismic excitation Step back structure could demonstrate more helpless than other setup of structures. 2. It is seen that, short segments draws in more powers and are most noticeably awful influenced during seismic excitation. From configuration perspective, uncommon consideration ought to be given to the size (quality), direction (solidness) and flexibility request of short segment. 3 . The slope incline structures are exposed to noteworthy torsional impacts, because of uneven circulation of shear power in the different edges of structure recommend advancement of torsional minute, which is observed to be higher in venture back building.4. Numerous specialists proposed as venture back set back structures might be supported on slanting ground. 5. From the examination it is inferred that the nearness of infill divider and shear divider impacts the conduct of structure by diminishing story relocation and story floats extensively, however may expand the base shear, thus exceptional consideration ought to be given in configuration to decrease base shear.

\section{SEISMIC DESIGN CODES}

Seismic codes are unique to a particular region or country. They take into account the local seismology, 
accepted level of seismic risk, building topologies, materials available in the locality and the methods used in the construction. In India we refer to Bureau of Indian Standards (BIS) which include the following seismic codes- IS 1893 Part 1)-2002: Indian standard Criteria for Earthquake Resistant Design (5th revision)-IS 1893-2002 is the main code for the earthquake resistant design which provides the seismic design force, seismic zone map and different factors and coefficient such as importance factor, seismic zone factor, stiffness, factor related to the soil on which structure rests, which are required in earthquake resistant design.

IS 13920-1993: Indian Standard code of Practice for Ductile Detailing of Reinforced Concrete Structure Subjected to Seismic Forces - In India, reinforced concrete structures are designed and detailed according to IS 456 (2002). However structures located in high seismic regions require ductile design and detailing.

\section{TERMINOLOGIES USED IN EARTHQUAKE}

Epicentre: The geographical point on the surface of earth vertically above the focus of the earthquake.

Hypocentre or Focus: The originating earthquake source of the elastic waves inside the earth which causes shaking of ground due to earthquake.

Epicentral distance: Distance between epicentre and recording station in $\mathrm{km}$.

Focal depth: The depth of focus from the epicentre is called focal depth. It is an important parameter in determining the damaging potential of an earthquake. Most of the damaging earthquakes have shallow focus with focal depths less than about $70 \mathrm{~km}$.

Fault: A fracture in the rocks along which strain is occasionally released as an earthquake. By definition, only active faults are associated with earthquakes.

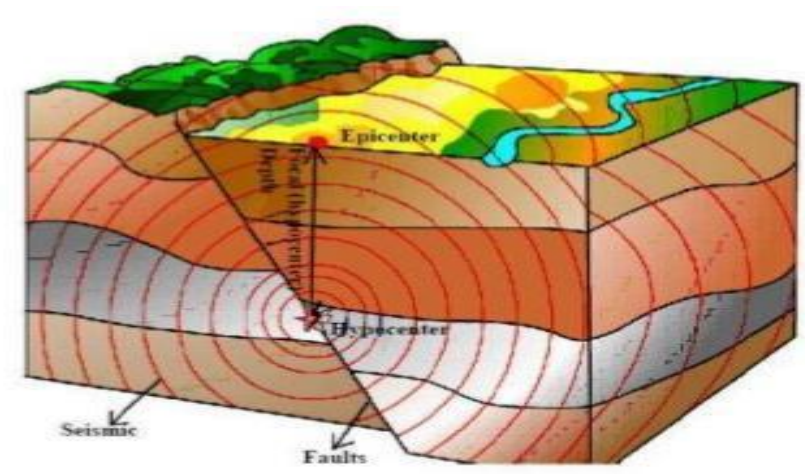

Fig: 1.5 Terminologies of earthquake

\section{MODELLING AND METHODOLOGY}

\section{Modeling of structures:}

In the present investigation three G+15 structure models with establishment profundity of $2 \mathrm{~m}$ and inlet widths long and width headings of $6 \mathrm{~m}$ each, bolster conditions are thought to be fixed at the base or at the backings/footings. The structures having length $=6 \times 10=60 \mathrm{~m}$, width $=6 \times 5=30 \mathrm{~m}$ and tallness $=20 \mathrm{~m}$. Ground inclines considered of edges 00 , 100.The structures displayed in ETABS auxiliary examination and plan programming by considering different loads and burden blends by their relative event are viewed as the material properties considered are M30 evaluation cement and Fe415 strengthening steel bars. Strategies for investigation considered are straight static examination, Response range investigation and Time history investigation.

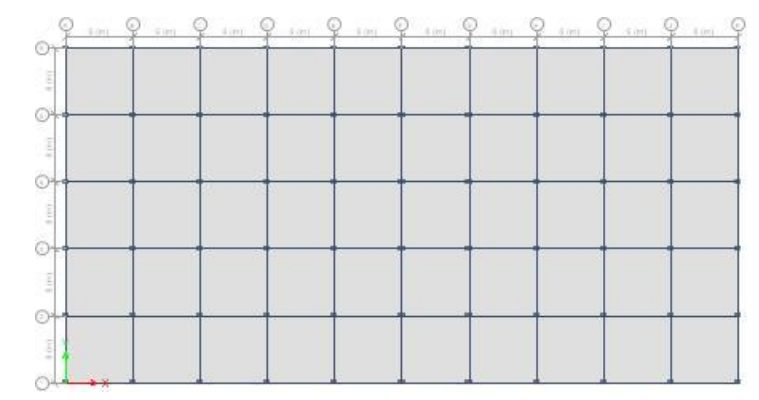

Fig 1.6 : floor plan of structure-1 and structure-2

\section{VII.CONCLUSION}

Coming up next are the outcomes drawn from the examination of G+15 structures laying on nonslanting and inclining ground levels by utilizing 
straight static, reaction range and time history investigation slants considered are 00 (structure-1)and 100(structure-2) seismic burdens are connected parallel to $\mathrm{x}$ and $\mathrm{y}$ bearings.

1. It is seen that with the expansion in the seismic zones from zone- 2 to zone- 5 the parameters, for example, bowing minutes, shear powers and redirections are in expanding request.

2. Shorter sections are seen to be stiffer than longer segments and are exposed to higher story powers.

3. Storey float, horizontal burden on story's and story shear and observed to be same in structure1 and structure-2

4. Lateral burden is observed to be $730 \mathrm{kN}$ in structure-1for direct static examination and $240 \mathrm{kN}$ for reaction range and time history investigation.

5. Lateral burden in structure-1 is diminished by $67.13 \%$ for reaction range and time history examination.

6. Lateral burden is observed to be $150 \mathrm{kN}$ in structure-2 for direct static examination, reaction range and time history investigation.

7. Storey shears are observed to be $7200 \mathrm{kN}$ in structure- 1 and $1600 \mathrm{kN}$ in structure-2

8. Maximum Support responses at the base are $4570.52 \mathrm{kN}, 13395.49 \mathrm{kN}$ and $184886 \mathrm{kN}$ for direct static, reaction range and time history examination.

9. Maximum Joint removals in structure-1 is $113.4 \mathrm{~mm}$ and in structure- 2 is $29.1 \mathrm{~mm}$

10. Column powers, for example, hub powers, shear powers and twisting minutes are observed to be less accordingly range examination for structure1 and 2 when contrasted and direct static and time history investigation

\section{REFERENCES}

[1]. Hajime Okamura and Masahiro Ouchi (2003), "Self-Compacting Concrete", Journal of Advanced
Concrete Technology Vol.1, No.1, 5-15, April 2003.

[2]. S. Venkateswara Rao, M.V. Seshagiri Rao, P. Rathish Kumar "Effect of Size of Aggregate and Fines on Standard And High Strength Self compacting Concrete", Journal of Applied Sciences Research, 6(5): 433-442, 2010.

[3]. "Specifications and guidelines for self-compacting concrete." published by EFNARC in February 2005.

[4]. Nan Su, Kung-Chung Hsu, His-Wen Chai, "A simple mix design method for self-compacting concrete", Cement and Concrete Research, 6 June 2001, pp1799-1807.

[5]. M.R.Arefi, M.R. Jahaveri, E. Mollaahmadi,(2011) Silica nanoparticle size effect on mechanical properties and microstructure of cement motar, Journal of American science.

[6]. A.A. Magsoudi, M.Magsoudi, and M. Noori, "Effect of Nanoparticles on SCC", second international conference on sustainable construction materials and technologies.June 28, 2010.

[7]. Ozawa K., Kunishima, M., Maekawa, K. and Ozawa, K, "Development of High Performance Concrete Based on the Durability Design of Concrete Structures". Proceedings of the second East-Asia and Pacific Conference on Structural Engineering and Construction (EASEC-2), Vol. 1, pp. 445-450, January 1989.

\section{Cite this article as :}

K. Hemanth, Shamshad Begum, "A Detailed Study on Earthquake Resistant Buildings on Ground Surface by Using E-Tabs", International Journal of Scientific Research in Science and Technology (IJSRST), Online ISSN : 2395-602X, Print ISSN : 2395-6011, Volume 8 Issue 4, pp. 619-625, July-August 2021. Available at doi $\quad$ : https://doi.org/10.32628/IJSRST218496 Journal URL : https://ijsrst.com/IJSRST218496 